\title{
Fractures among long-term survivors of childhood cancer: A report from the Childhood Cancer Survivor Study
}

\author{
Carmen L. Wilson, PhD ${ }^{1}$, Kimberley Dilley, MD, MPH ${ }^{2}$, Kirsten K. Ness, PhD, PT ${ }^{1}$, Wendy L. \\ Leisenring, $\mathrm{ScD}^{3}$, Charles A. Sklar, $\mathrm{MD}^{4}$, Sue C. Kaste, $\mathrm{DO}^{5}$, Marilyn Stovall, $\mathrm{PhD}^{6}$, Daniel \\ M. Green, MD ${ }^{1}$, Gregory T. Armstrong, MD, MSCE ${ }^{1}$, Leslie L. Robison, PhD $^{1}$, and Nina S. \\ Kadan-Lottick, MD ${ }^{7}$ \\ ${ }^{1}$ St. Jude Children's Research Hospital, Epidemiology and Cancer Control, 262 Danny Thomas \\ Place, Memphis, TN 38105 \\ ${ }^{2}$ Children's Memorial Hospital, Pediatrics, 2300 Children's Plaza, Chicago, IL 60614 \\ ${ }^{3}$ Fred Hutchinson Cancer Research Center, Clinical Statistics and Cancer Prevention, 1100 \\ Fairview Ave. No. D5-360 Seattle, WA 98109 \\ ${ }^{4}$ Memorial Sloan Kettering Cancer, Department of Pediatrics, 1275 New York Ave, New York, NY \\ 10021 \\ ${ }^{5}$ St. Jude Children's Research Hospital, Department of Radiological Sciences, Department of \\ Oncology, 262 Danny Thomas Place, Memphis, TN 38105 \\ 6University of Texas M.D. Anderson Cancer Center, 1515 Holcombe Blvd Box 605, Houston, TX \\ 77030 \\ ${ }^{7}$ Yale University School of Medicine, Division of Pediatric Hematology-Oncology, 333 Ceder \\ Street, LMP-4087, New Haven, CT 06520
}

\section{Abstract}

Background-Although reductions in bone mineral density are well-documented among children during treatment for cancer and among childhood cancer survivors, little is known about the long-term risk of fracture. The aim of this study was to ascertain the prevalence of and risk factors for fractures among individuals participating in the Childhood Cancer Survivor Study (CCSS).

Methods-Analyses included $74145+$ year survivors of childhood cancer diagnosed between 1970-86 who completed the 2007 CCSS follow-up questionnaire and a comparison group of 2374 siblings. Generalized linear models stratified by sex were used to compare the prevalence of reported fractures between survivors and siblings.

Results-The median ages at follow-up among survivors and siblings were 36.2, (range: 21.2-58.8) and 38.1 years (range: 18.4-62.6), respectively with a median 22.7 years of follow-up after cancer diagnosis for survivors. Approximately 35\% of survivors and 39\% of siblings reported $\geq 1$ fractures during their lifetime. The prevalence of fractures was lower among survivors than siblings, both in males (prevalence ratio $=0.87,95 \% \mathrm{CI}=0.81-0.94, \mathrm{p}<0.001$ ) and females (prevalence ratio $=0.94,95 \% \mathrm{CI}=0.86-1.04, \mathrm{p}=0.22$ ). In multivariable analyses, increasing age at follow-up, white race, methotrexate treatment and balance difficulties were associated with

Corresponding author: Carmen Wilson, Department of Epidemiology \& Cancer Control, St. Jude Children's Research Hospital, 262 Danny Thomas Place, Memphis, TN 38105, MS-735, Telephone - 901.595.6462, Facsimile - 901.595.5845,

carmen.wilson@stjude.org.

Financial disclosures: The authors have no financial interests to disclose. 
increased prevalence of fractures among female survivors $(\mathrm{p}=0.05)$. Among males, only smoking history and white race were associated with an increased prevalence of fracture $(\mathrm{p}<0.001)$.

Conclusions-Findings from this study indicate that the prevalence of fractures among adult survivors is not increased compared to that of siblings. Additional studies of bone health among aging female cancer survivors may be warranted.

\section{Introduction}

Survivors of childhood cancer are at risk of developing bone-related late effects as a result of disturbances in bone metabolism during childhood or adolescence. Attainment of normal peak bone mass may be compromised by the effects of the cancer experience, such as nutritional deficiencies and reduced exercise capacity, ${ }^{1,2}$ or because normal bone mineral accretion and skeletal development are affected by corticosteroids and other chemotherapeutic agents (eg, methotrexate).$^{2-4}$ Bone mineral density (BMD) can be adversely affected by gonadal failure following exposure to radiation, gonadotoxic chemotherapy, or as a consequence of hypothalamic pituitary dysfunction following irradiation to the central nervous system. ${ }^{5,6}$ Moreover, direct radiation to bone causes cytotoxic effects on the epiphyseal chondrocytes ${ }^{9}$, increased hypervascularity, and reduced bone strength. ${ }^{7,8}$

Deficits in BMD among survivors of childhood cancer have been well-documented in numerous studies. ${ }^{9-12}$ Among children being treated for acute lymphoblastic leukemia (ALL), bone mass has been observed to decrease significantly during treatment ${ }^{13-15}$ followed by a return to lower than average value (though still within the normal range) in the years following the completion of therapy. ${ }^{16}$ In the general population, reduced BMD is a major public health concern as decrements in BMD can significantly increase the risk of fracture, which in turn is associated with elevated rates of disability and mortality, and high socio-economic costs. ${ }^{17-19}$ Accordingly, failure to accrue sufficient bone mass during childhood and adolescence may increase the risk for early onset osteoporosis among childhood cancer survivors and place them at risk for fracture later in life. Despite this, the occurrence of fracture among long-term survivors remains largely uncharacterized. Previous studies that have measured fracture risk among survivors have examined only fractures occurring during treatment or within the first five years of completing therapy. ${ }^{13,15}$ Thus, it is not clear whether alterations to bone metabolism during therapy impact post-therapy risk of fractures. Moreover, most studies of fracture risk among survivors have been restricted to individuals previously treated for ALL or malignancies of the central nervous system, ${ }^{13,15,20}$ or had small sample sizes that limited the consideration of additional factors, such as demographic and lifestyle factors, on fracture risk.

The purpose of this study is to describe the history of reported fractures among a large and diverse cohort of cancer survivors, and to identify treatment- and host- related factors that predispose survivors to an increased risk of fracture. A major advantage of this study is the availability of detailed information on treatment, health-related behaviors, physical activity levels, body mass index (BMI) and balance and movement disorders, which may predispose survivors to increased risk for fracture as they age.

\section{Methods}

The CCSS is a multisite, retrospective cohort designed to study the late effects of childhood cancer therapy. Potential study participants were identified from 26 participating institutions across the United States and Canada based on the following criteria; diagnosis of leukemia, central nervous system (CNS) malignancy, Hodgkin lymphoma, non-Hodgkin lymphoma, malignant kidney tumor, neuroblastoma, soft tissue sarcoma or bone tumor; diagnosis date 
between January 1, 1970 and December 31, 1986; age younger than 21 years at diagnosis; and alive five years from the date of diagnosis. Information relating to each study participant's original cancer diagnosis and treatment was abstracted from medical records held at participating centers. The CCSS study protocol and cohort characteristics have been described previously 21,22 and are available at http://www.stjude.org/ccss. All CCSS protocol and contact documents were reviewed and approved by the human subjects committee at each participating institution.

Of the 20,691 survivors of childhood cancer eligible for participation, 17,633 were successfully contacted and 14,358 completed the baseline questionnaire. Of the 14,358 initial participants, 8,013 completed the 2007 follow-up questionnaire (Figure 1). A random sample of participating cancer survivors $(n=6100)$ was asked to contact their sibling closest in age for participation in the study. Of these, 4828 stated willingness to participate and were sent a questionnaire. Of these 4023 siblings completed the baseline questionnaire, and 2374 siblings completed the 2007 follow-up questionnaire.

The primary outcome measure for these analyses was the occurrence of a fracture among study participants. Self-report data from the 2007 follow-up questionnaire were used to characterize fracture history. Participants were asked if they had "ever broken a bone". If the participant's response to this question was "yes," he/she was then asked to provide further details regarding their previous fracture(s).

Information about medical conditions or functional limitations potentially associated with fracture risk and about physical activity, height and weight were also obtained from the 2007 questionnaire. Participants were asked to report if they had ever been diagnosed with problems affecting their balance or equilibrium, and to grade the extent of their problem from mild (not affecting walking or daily routine) to disabling. Respondents reporting a moderate to disabling problem were considered to experience difficulties with balance and equilibrium. Vision loss was defined as a diagnosis of legal blindness in one or both eyes. Smoking history was categorized as ever vs. never. Body mass index was calculated as weight $(\mathrm{kg})$ divided by height $(\mathrm{m})$ squared and classified as underweight $\left(<18.5 \mathrm{~kg} / \mathrm{m}^{2}\right)$, normal $\left(20-24.9 \mathrm{~kg} / \mathrm{m}^{2}\right)$, overweight $\left(25-29.9 \mathrm{~kg} / \mathrm{m}^{2}\right)$, and obese $\left(\geq 30 \mathrm{~kg} / \mathrm{m}^{2}\right)$. Physical activity was classified as meeting (yes/no) the Centers for Disease Control and Prevention (CDC) guidelines for physical activity (30 minutes of moderate intensity physical activity on five or more days of the week or 20 minutes of vigorous activity three or more days a week). Functional ability was determined based on the participant's responses to five questions, adapted from the National Health Interview Survey, that asked participants if their health over the past two years was limited for more than three months in "(1) the kinds or amounts of moderate activities you can do, like moving a table, carrying groceries, or bowling; (2) walking uphill or climbing a few flights of stairs; (3) bending, lifting or stooping; (4) walking one block; or (5) eating, dressing or bathing." 23

In addition to health status, selected chemotherapeutic agent exposure (methotrexate and alkylating agents), as well as glucocorticoids, were considered in analyses based on prior knowledge of the influence of these agents on bone metabolism. ${ }^{2-5}$ Cumulative doses of glucocorticoids were unavailable. Central nervous system and pelvic radiation exposures and surgical procedures, including amputation of the lower limb (transtibial, transfemoral or hemipelvectomy), and bilateral orchiectomy and bilateral oophorectomy were obtained from medical records. Exposure to selected chemotherapeutic agents and pelvic radiotherapy, as well as the occurrence of an amputation were classified as dichotomous variables for analyses. Radiation exposure to the hypothalamus and pituitary was categorized as no exposure, between 1 and 2000cGy, or $>2000$ cGy. Bilateral orchiectomy and bilateral oophorectomy were not considered in further analyses due to the small number of cases who 
had undergone these procedures $(n<20)$. Finally, data on current usage of agents known to promote bone health including hormone replacement therapies, bisphosphonates, vitamin $\mathrm{D}$ and calcium supplements, were also considered in analyses.

The demographic and treatment characteristics of survivors participating in the current study were compared against those survivors who did not complete the CCSS 2007 follow-up questionnaire, that is, non-participants, using the chi-square statistic. Descriptive statistics were calculated for demographic and health characteristics and compared between survivors and siblings. Generalized linear models, stratified by sex, were used to compare the history of fractures between survivors and siblings. Generalized estimating equations (GEE) with robust variance estimates were used to account for intra-family correlation. Results were presented as prevalence ratios (PRs) with 95\% confidence intervals (CI). The influence of selected factors on the history of fractures among survivors only was also evaluated using generalized linear models (log-link with binomial distribution) stratified by sex. Factors considered in the analysis included smoking status, BMI, physical activity, vision loss, difficulties with balance and equilibrium, functional health status and treatment type. Only those variables that demonstrated $p$-values of $<0.2$ in bivariate models were considered in multivariable models. All models were adjusted for ethnicity, attained age and age at diagnosis. All analyses were performed using the statistical package SAS Version 9.2 (Cary, North Carolina).

\section{Results}

The median ages at follow-up among cancer survivors and siblings were 36.2, (range: 21.2-58.8) and 38.1 years (range: 18.4-62.6), respectively. The median age at diagnosis was 6.9 years (range: $0-21$ ) for survivors and the median length of follow-up was 22.7 years (range: 15.6-34.2). Among both cancer survivors and their siblings, the majority of participants were of white, non-Hispanic descent (>89\%, Table 1). When compared to siblings, survivors were less likely to have ever smoked ( $\mathrm{p}<0.001)$. When compared to nonparticipants, survivors were more likely to be female $(50.6 \%$ vs. $42.1 \%$, p <0.001) and of white, non-Hispanic descent (90.8\% vs. $79.9 \%, \mathrm{p}<0.001)$, In addition, a higher proportion of survivors received glucocorticoids (46.8\% vs. $34.9 \%)$ or methotrexate (43.6\% vs. $31.4 \%)$ than non-participants. Of note, data regarding chemotherapeutic exposures were unavailable for approximately $30 \%$ of non-participants.

Over a third of survivors (34.8\%) and siblings (38.9\%) reported the occurrence of one or more fractures during their lifetime. As seen in Table 2, the most frequently reported site of occurrence of a fracture was the upper limb for both survivors (54.9\%) and siblings (55.6\%) followed by fractures of the lower limb and skull. The distribution of the total number of fractures reported by participants did not vary between survivors and siblings (Table 3 , $\mathrm{p}>0.05$ ). After adjusting for attained age, ethnicity, smoking status, BMI and history of medications known to promote bone health, male survivors of childhood cancer were less likely to report a fracture than their siblings ( $\mathrm{PR}=0.87,95 \% \mathrm{CI}=0.81-0.94, \mathrm{p}<0.001)$. Although the reported prevalence of fractures was also lower among female survivors when compared to their sibling counterparts $(\mathrm{PR}=0.94,95 \% \mathrm{CI}=0.86-1.04, \mathrm{p}=0.22)$, this association did not meet significance at an alpha (a) level of $\mathrm{p}=0.05$.

Generalized linear models stratified by sex were used to examine the influence of selected characteristics on the prevalence of fractures among survivors of childhood cancer. In multivariable analyses, male survivors of non-white ethnic descent were less likely to report a fracture than white participants $(\mathrm{PR}=0.78,95 \% \mathrm{CI}=0.66-0.92, \mathrm{p}=0.004)$. Only prior smoking history $(\mathrm{PR}=1.24,95 \% \mathrm{CI}=1.14-1.34, \mathrm{p}<0.001)$ was associated with an increased prevalence of fracture (Table 4). Among female survivors, an association between 
increasing age at follow-up and an increased prevalence of fractures was observed, with survivors aged between $40-49$ years, and more than 50 years $1.22-(95 \% \mathrm{CI}=1.01-1.48$, $\mathrm{p}=0.044)$ and 1.48 -times $(95 \% \mathrm{CI}=1.10-1.99, \mathrm{p}=0.009)$ more likely to report a fracture than those survivors aged between 18-29 years. Female survivors who reported difficulties with balance or equilibrium $(\mathrm{PR}=1.25,95 \% \mathrm{CI}=1.05-1.48, \mathrm{p}=0.012)$, or who had received methotrexate treatment $(\mathrm{PR}=1.15,95 \% \mathrm{CI}=1.03-1.27, \mathrm{p}=0.001)$ also reported an increased prevalence of fracture in multivariable analyses.

Presented in Table 5 is a comparison of the prevalence of fractures among individual cancer diagnostic groupings compared to siblings. Among male survivors, history of any diagnosis except non-Hodgkin lymphoma and bone tumors was associated with a decreased risk of fracture when compared to siblings. The prevalence of fracture was observed to be significantly reduced only among female survivors of kidney tumors $(\mathrm{PR}=0.76$, $95 \% \mathrm{CI}=0.62-0.93, \mathrm{p}=0.009)$. The only diagnostic group observed to have a higher prevalence of fracture compared to the sibling control group was female survivors of bone tumors $(\mathrm{PR}=1.15,95 \% \mathrm{CI}=0.97-1.36)$, although this finding was not statistically significant at $\mathrm{p}=0.05$.

\section{Discussion}

The aim of this study was to characterize history of fractures in a large cohort of adult survivors of childhood cancer, and to identify patient and treatment characteristics associated with fractures. To date only a limited number of studies have examined the risk of fracture among childhood cancer survivors and findings have been contradictory. $., 10,20$ In the current study, we found the prevalence of reported fractures to be comparable between female survivors of childhood cancer and their siblings, while among males, the prevalence of fracture was lower among survivors relative to the sibling control group. Furthermore, we did not observe any meaningful differences in the total number of reported fractures or the distribution of fractures by site between survivors and their siblings.

Although numerous studies have reported an increased risk of BMD deficits among children being treated for cancer or shortly after finishing therapy, it is not clear what the implications of anti-cancer therapies on bone mass and fracture risk are among long-term survivors. In fact, some investigators have observed that BMD values for many survivors will return to the normal range in the years following the completion of therapy. ${ }^{16}$ Accordingly, for survivors participating in the current study, BMD may recover sufficiently with time so as not to increase the risk of fractures above that of their siblings. However, it is also important to consider that BMD is not the only factor that mediates the risk of fracture as bone strength is also in part determined by the inherent structural and material properties of bone, including geometry, trabecular thickness and connectivity, cortical porosity, mineral to matrix ratio, and collagen composition. ${ }^{24,}{ }^{25}$ While these abnormalities in bone quality and strength have been shown to increase the propensity to fracture, ${ }^{26-28}$ little is known about the structural and material properties of bone among adult survivors of childhood cancer and how these properties are affected by anti-cancer treatments. It is possible that among survivors with deficits in BMD, reduced bone mass may not be sufficient to increase fracture risk substantially, but that corresponding impairment in bone quality and strength may also be necessary. Thus, further studies characterizing additional measures of bone strength and quality (i.e. bone geometry), as well as BMD may be important for understanding the etiology of fractures among adult survivors of childhood cancer.

In addition to bone quality and strength, factors that increase the propensity to fall, such as impairments in vision, neuromotor coordination, postural control and muscle function, may 
also increase fracture risk. In the current study, we observed an increased risk of fractures among female survivors who reported difficulties with balance and equilibrium, which is consistent with findings from a previous study in breast cancer survivors, ${ }^{29}$ as well as reports carried out in non-oncological populations. ${ }^{30,31}$ Among survivors of childhood cancer, difficulties with balance and equilibrium may be the result of therapy with platinumbased agents, which can damage the organs of the inner ear, impairing vestibular function. Damage to the nerve fibers of the hands, legs and feet, can also occur following vincristine or platinum therapy. ${ }^{327,33}$ Our findings suggest that the presence of chronic health conditions following therapy for childhood cancer, such as deficits in balance, may increase the risk of fracture among survivors. However, not all chronic health conditions that increase skeletal fragility or the propensity to fall were associated with increased fracture risk in our study.

In the current study, an association between increasing age at follow-up with a higher prevalence of fracture was observed among female survivors. In the general population, rates of fracture begin to rise substantially among women in their fifties coinciding with declines in estrogen that occur following menopause. ${ }^{24-25}$ Previous findings from the CCSS have shown that female survivors of childhood cancer are more likely to enter menopause prematurely when compared to their siblings. ${ }^{34}$ Accordingly, our observation of an increasing prevalence of fracture among aging female survivors may in part be due to an earlier decline in estrogen production among them. However, we did not observe an association between exposure to alkylating agents or pelvic irradiation with an increased prevalence of fracture. The absence of an association may, in part, be explained by hormonal replacement therapies among female survivors diagnosed with hypogonadism. It is also possible that failure to reach peak genetic potential during adolescence and early adulthood, due to the effects of disease and anti-cancer treatments on normal bone accrual, may have promoted the premature onset of age-related fracture among older females in our survivor cohort. While the underlying reason for our observation is unclear, our finding suggests that further studies of bone health among aging female cancer survivors may be warranted.

A limitation of this study was the use of self-report questionnaires to collect information on the occurrence of fractures and other health-related information among survivors of childhood cancer and their siblings. The reliability of this approach was dependent on a study participant's ability to report the occurrence of prior fractures, and consequently, biases in recall may have impacted our ability to estimate the prevalence of fractures in the study cohort. We are reassured that the validity of self-reports for fractures is high based on previous studies in both men and women. ${ }^{35}$ This study was also limited by the absence of data on BMD, which prevented us from evaluating potential associations between fracture risk and BMD in the study population. Finally, the higher proportion of females and individuals of white, non-Hispanic descent among survivors who completed the CCSS 2007 follow-up questionnaire may limit our ability to generalize findings to males and to survivors of non-white descent. Although we also observed that a higher proportion of participants who received glucocorticoids and methotrexate also completed the CCSS 2007 follow-up questionnaire, these observations are difficult to interpret given the high number of non-participants for whom treatment information were unavailable.

Overall, the findings from this study indicate that the prevalence of fracture among longterm adult survivors of childhood cancer is similar to that of siblings despite chemotherapy and radiation exposure known to disrupt bone metabolism during therapy. Nevertheless, caution is required when interpreting these results as the majority of study participants have yet to reach an age where the underlying population risk of fracture increases substantially. The long-term trajectory of BMD deficits following anti-cancer therapies in childhood is poorly defined and little is known about the potential effects of chemotherapy and 
radiotherapy upon the bone health of ageing survivors. Moving forward, it will be important to characterize long-term skeletal morbidities in post-menopausal and aging childhood cancer populations.

\section{Acknowledgments}

Funding: This project was funded by grant number U24CA055727 (L. L. Robison, Principal Investigator) from the National Cancer Institute. Additional funding provided by St Jude Children's Research Hospital Cancer Center Support Grant (number 5P30CA021765-33). Dr. Kadan-Lottick is supported in part by American Cancer Society Scholar Grant 119700-RSGHP-10-107-01-CPHPS

\section{References}

1. Atkinson SA, Halton JM, Bradley C, Wu B, Barr RD. Bone and mineral abnormalities in childhood acute lymphoblastic leukemia: influence of disease, drugs and nutrition. Int J Cancer Suppl. 1998; 11:35-9. [PubMed: 9876475]

2. Warner JT, Evans WD, Webb DK, Bell W, Gregory JW. Relative osteopenia after treatment for acute lymphoblastic leukemia. Pediatr Res. 1999; 45(4 Pt 1):544-51. [PubMed: 10203147]

3. Gnudi S, Butturini L, Ripamonti C, Avella M, Bacci G. The effects of methotrexate (MTX) on bone. A densitometric study conducted on 59 patients with MTX administered at different doses. Ital J Orthop Traumatol. 1988; 14(2):227-31. [PubMed: 3220728]

4. Meister B, Gassner I, Streif W, Dengg K, Fink FM. Methotrexate osteopathy in infants with tumors of the central nervous system. Med Pediatr Oncol. 1994; 23(6):493-6. [PubMed: 7935176]

5. Henderson RC, Madsen CD, Davis C, Gold SH. Bone density in survivors of childhood malignancies. J Pediatr Hematol Oncol. 1996; 18(4):367-71. [PubMed: 8888743]

6. Hesseling PB, Hough SF, Nel ED, van Riet FA, Beneke T, Wessels G. Bone mineral density in long-term survivors of childhood cancer. Int J Cancer Suppl. 1998; 11:44-7. [PubMed: 9876477]

7. Nyaruba MM, Yamamoto I, Kimura H, Morita R. Bone fragility induced by X-ray irradiation in relation to cortical bone-mineral content. Acta Radiol. 1998; 39(1):43-6. [PubMed: 9498868]

8. Wagner LM, Neel MD, Pappo AS, et al. Fractures in pediatric Ewing sarcoma. J Pediatr Hematol Oncol. 2001; 23(9):568-71. [PubMed: 11902298]

9. Brennan BM, Rahim A, Adams JA, Eden OB, Shalet SM. Reduced bone mineral density in young adults following cure of acute lymphoblastic leukaemia in childhood. Br J Cancer. 1999; 79(11-12): 1859-63. [PubMed: 10206305]

10. Kaste SC, Rai SN, Fleming K, et al. Changes in bone mineral density in survivors of childhood acute lymphoblastic leukemia. Pediatr Blood Cancer. 2006; 46(1):77-87. [PubMed: 16106430]

11. Holzer G, Krepler P, Koschat MA, Grampp S, Dominkus M, Kotz R. Bone mineral density in long-term survivors of highly malignant osteosarcoma. J Bone Joint Surg Br. 2003; 85(2):231-7. [PubMed: 12678358]

12. Barr RD, Simpson T, Webber CE, et al. Osteopenia in children surviving brain tumours. Eur J Cancer. 1998; 34(6):873-7. [PubMed: 9797700]

13. Halton JM, Atkinson SA, Fraher L, et al. Altered mineral metabolism and bone mass in children during treatment for acute lymphoblastic leukemia. J Bone Miner Res. 1996; 11(11):1774-83. [PubMed: 8915786]

14. Henderson RC, Madsen CD, Davis C, Gold SH. Longitudinal evaluation of bone mineral density in children receiving chemotherapy. J Pediatr Hematol Oncol. 1998; 20(4):322-6. [PubMed: 9703005]

15. van der Sluis IM, van den Heuvel-Eibrink MM, Hahlen K, Krenning EP, de Muinck KeizerSchrama SM. Altered bone mineral density and body composition, and increased fracture risk in childhood acute lymphoblastic leukemia. J Pediatr. 2002; 141(2):204-10. [PubMed: 12183715]

16. Kadan-Lottick N, Marshall JA, Baron AE, Krebs NF, Hambidge KM, Albano E. Normal bone mineral density after treatment for childhood acute lymphoblastic leukemia diagnosed between 1991 and 1998. J Pediatr. 2001; 138(6):898-904. [PubMed: 11391336] 
17. Johnell O, Kanis JA, Oden A, et al. Predictive value of BMD for hip and other fractures. J Bone Miner Res. 2005; 20(7):1185-94. [PubMed: 15940371]

18. Marshall D, Johnell O, Wedel H. Meta-analysis of how well measures of bone mineral density predict occurrence of osteoporotic fractures. BMJ. 1996; 312(7041):1254-9. [PubMed: 8634613]

19. Vega E, Ghiringhelli G, Mautalen C, Rey Valzacchi G, Scaglia H, Zylberstein C. Bone mineral density and bone size in men with primary osteoporosis and vertebral fractures. Calcif Tissue Int. 1998; 62(5):465-9. [PubMed: 9541527]

20. van der Sluis IM, van den Heuvel-Eibrink MM, Hahlen K, Krenning EP, de Muinck KeizerSchrama SM. Bone mineral density, body composition, and height in long-term survivors of acute lymphoblastic leukemia in childhood. Med Pediatr Oncol. 2000; 35(4):415-20. [PubMed: 11025472]

21. Leisenring WM, Mertens AC, Armstrong GT, et al. Pediatric cancer survivorship research: experience of the Childhood Cancer Survivor Study. J Clin Oncol. 2009; 27(14):2319-27. [PubMed: 19364957]

22. Robison LL, Mertens AC, Boice JD, et al. Study design and cohort characteristics of the Childhood Cancer Survivor Study: a multi-institutional collaborative project. Med Pediatr Oncol. 2002; 38(4):229-39. [PubMed: 11920786]

23. Centers for Disease Control and Prevention (CDC). National Health Interview Survey. US Dept of Human Health Services, Centers for Disease Control and Prevention; Atlanta, Ga: CDC: 1993.

24. Lane NE. Epidemiology, etiology, and diagnosis of osteoporosis. Am J Obstet Gynecol. 2006; 194(2 Suppl):S3-11. [PubMed: 16448873]

25. Seeman E. The structural and biomechanical basis of the gain and loss of bone strength in women and men. Endocrinol Metab Clin North Am. 2003; 32(1):25-38. [PubMed: 12699291]

26. Bailey AJ, Sims TJ, Ebbesen EN, Mansell JP, Thomsen JS, Mosekilde L. Age-related changes in the biochemical properties of human cancellous bone collagen: relationship to bone strength. Calcif Tissue Int. 1999; 65(3):203-210. [PubMed: 10441651]

27. Ferguson SJ, Steffen T. Biomechanics of the aging spine. Eur Spine J. 2003; 12(Suppl 2):S97S103. [PubMed: 13680317]

28. Skaggs DL, Loro ML, Pitukcheewanont P, Tolo V, Gilsanz V. Increased body weight and decreased radial cross-sectional dimensions in girls with forearm fractures. J Bone Miner Res. 2001; 16(7):1337-1342. [PubMed: 11450710]

29. Winters-Stone KM, Torgrimson B, Horak F, et al. Identifying factors associated with falls in postmenopausal breast cancer survivors: a multi-disciplinary approach. Arch Phys Med Rehabil. 2011; 92(4):646-52. [PubMed: 21367394]

30. Wagner H, Melhus H, Gedeborg R, Pedersen NL, Michaelsson K. Simply ask them about their balance--future fracture risk in a nationwide cohort study of twins. Am J Epidemiol. 2009; 169(2): 143-9. [PubMed: 19064648]

31. Muir SW, Berg K, Chesworth B, Klar N, Speechley M. Quantifying the magnitude of risk for balance impairment on falls in community-dwelling older adults: a systematic review and metaanalysis. J Clin Epidemiol. 2010; 63(4):389-406. [PubMed: 19744824]

32. Hockenberry M, Krull K, Moore K, Gregurich MA, Casey ME, Kaemingk K. Longitudinal evaluation of fine motor skills in children with leukemia. J Pediatr Hematol Oncol. 2007; 29(8): 535-9. [PubMed: 17762494]

33. Postma TJ, Benard BA, Huijgens PC, Ossenkoppele GJ, Heimans JJ. Long-term effects of vincristine on the peripheral nervous system. J Neurooncol. 1993; 15(1):23-7. [PubMed: 8384253]

34. Sklar CA, Mertens AC, Mitby P, et al. Premature menopause in survivors of childhood cancer: a report from the childhood cancer survivor study. J Natl Cancer Inst. 2006; 98(13):890-6. [PubMed: 16818852]

35. Ismail AA, O'Neill TW, Cockerill W, et al. Validity of self-report of fractures: results from a prospective study in men and women across Europe. EPOS Study Group. European Prospective Osteoporosis Study Group. Osteoporos Int. 2000; 11(3):248-54. [PubMed: 10824241] 


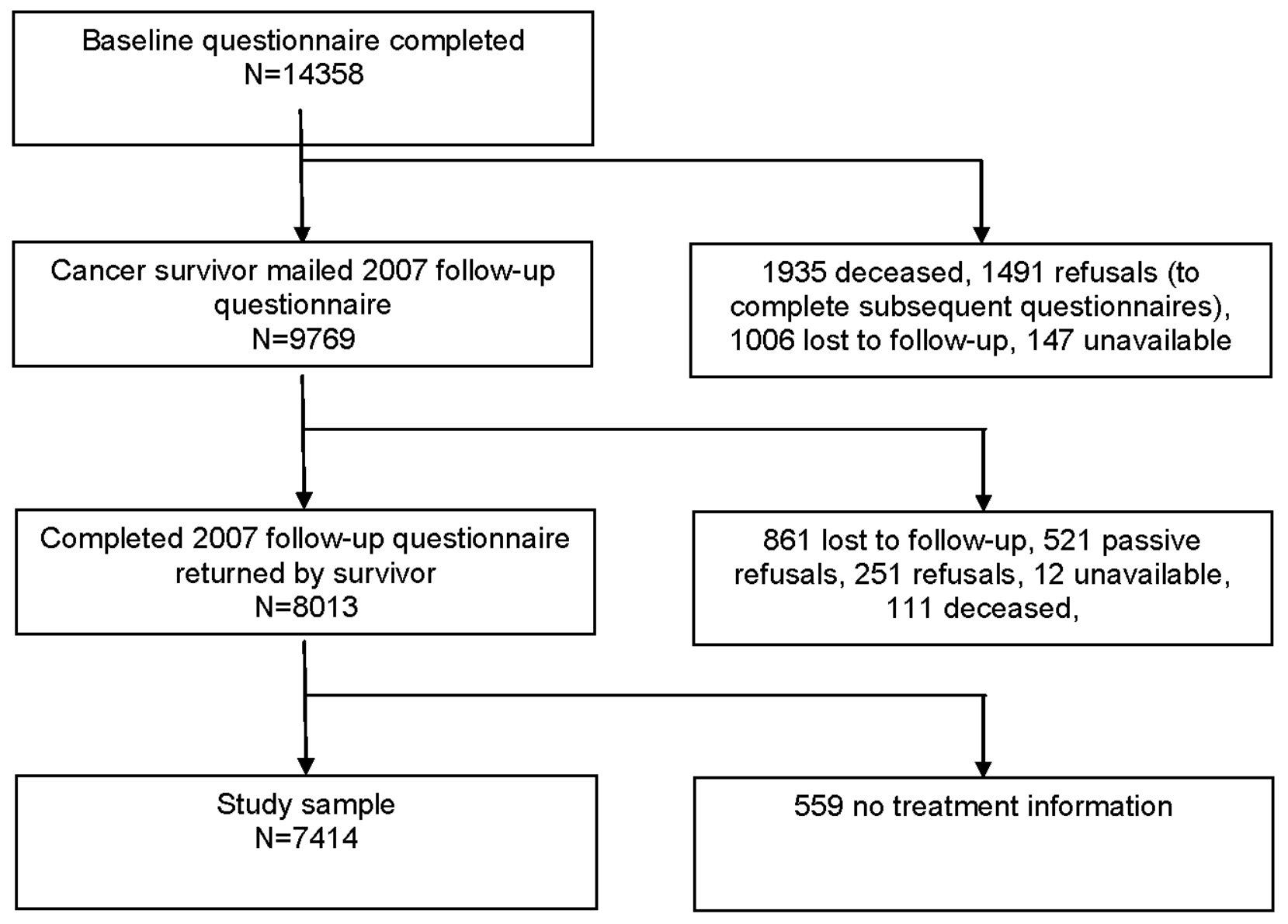

Figure 1. Flow diagram of study participation of cancer survivors from the Childhood Cancer Survivor Study 
$\stackrel{4}{\rightarrow} \stackrel{\sqrt[n]{3}}{3} \stackrel{4}{3}$

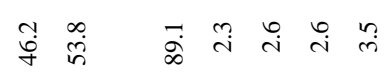

ㅇํㄹ

I.

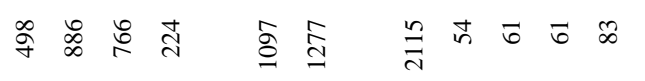

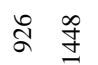

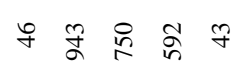

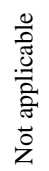

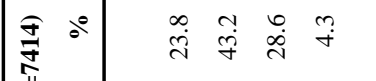

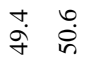

$\stackrel{8}{\infty}$ में

$\vec{i} \dot{8}$

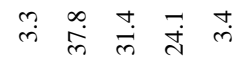

$\stackrel{n}{\stackrel{n}{m}} \stackrel{?}{\sim}$

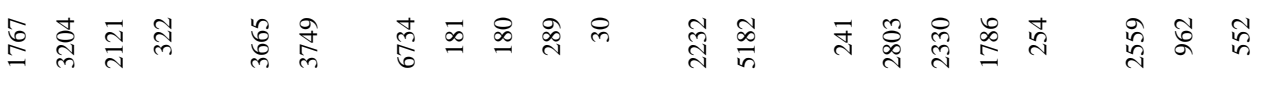




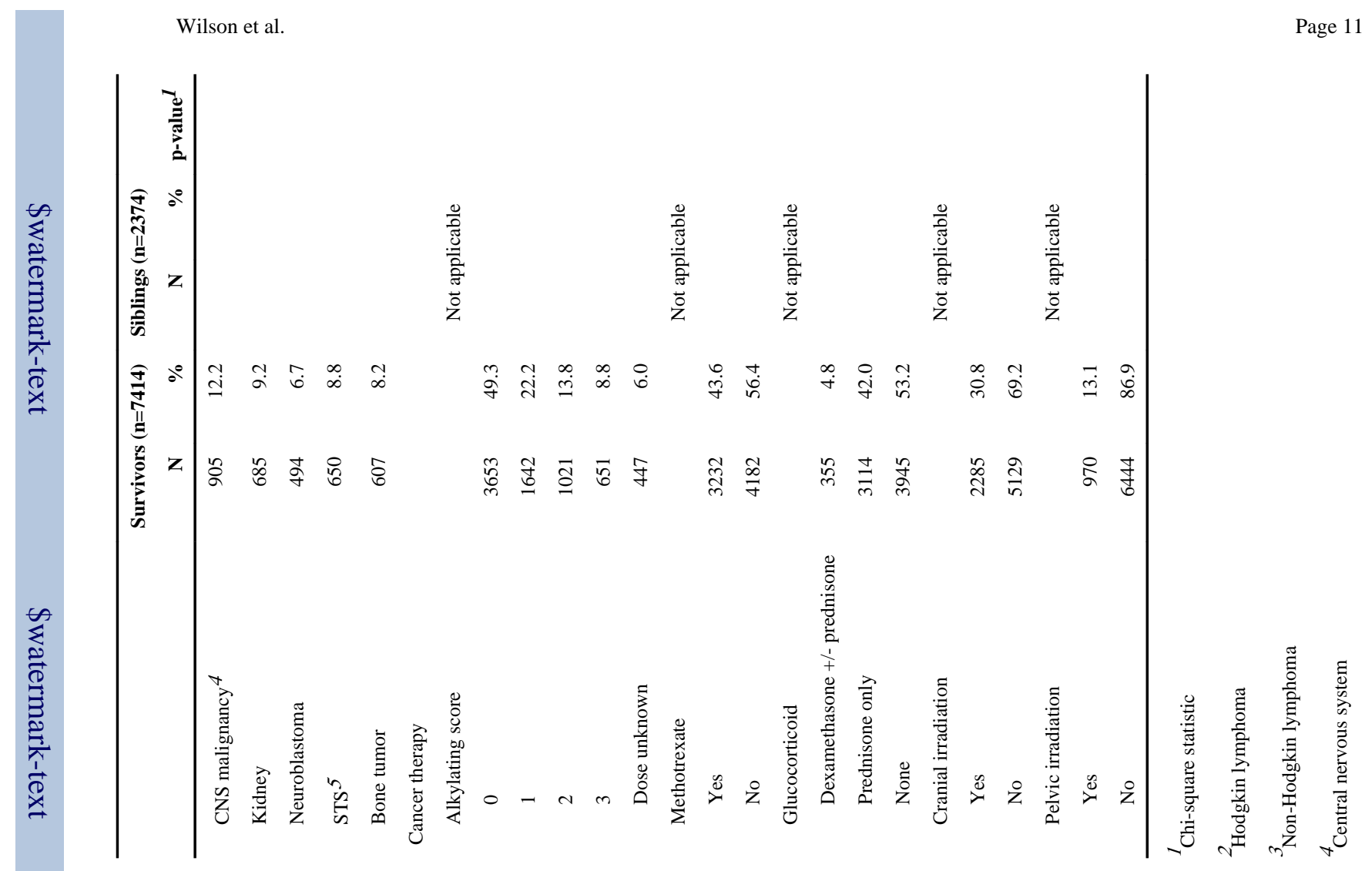




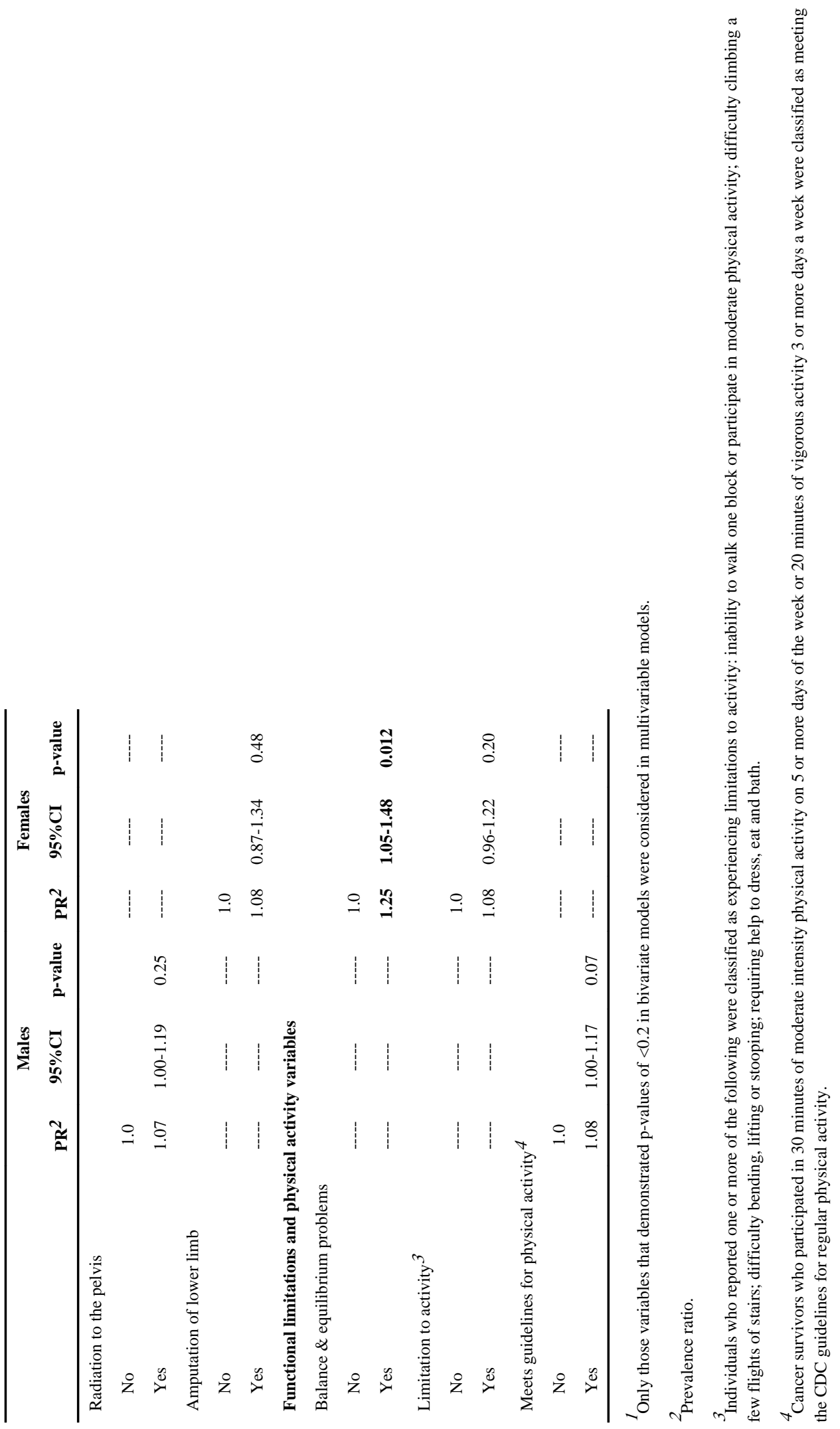




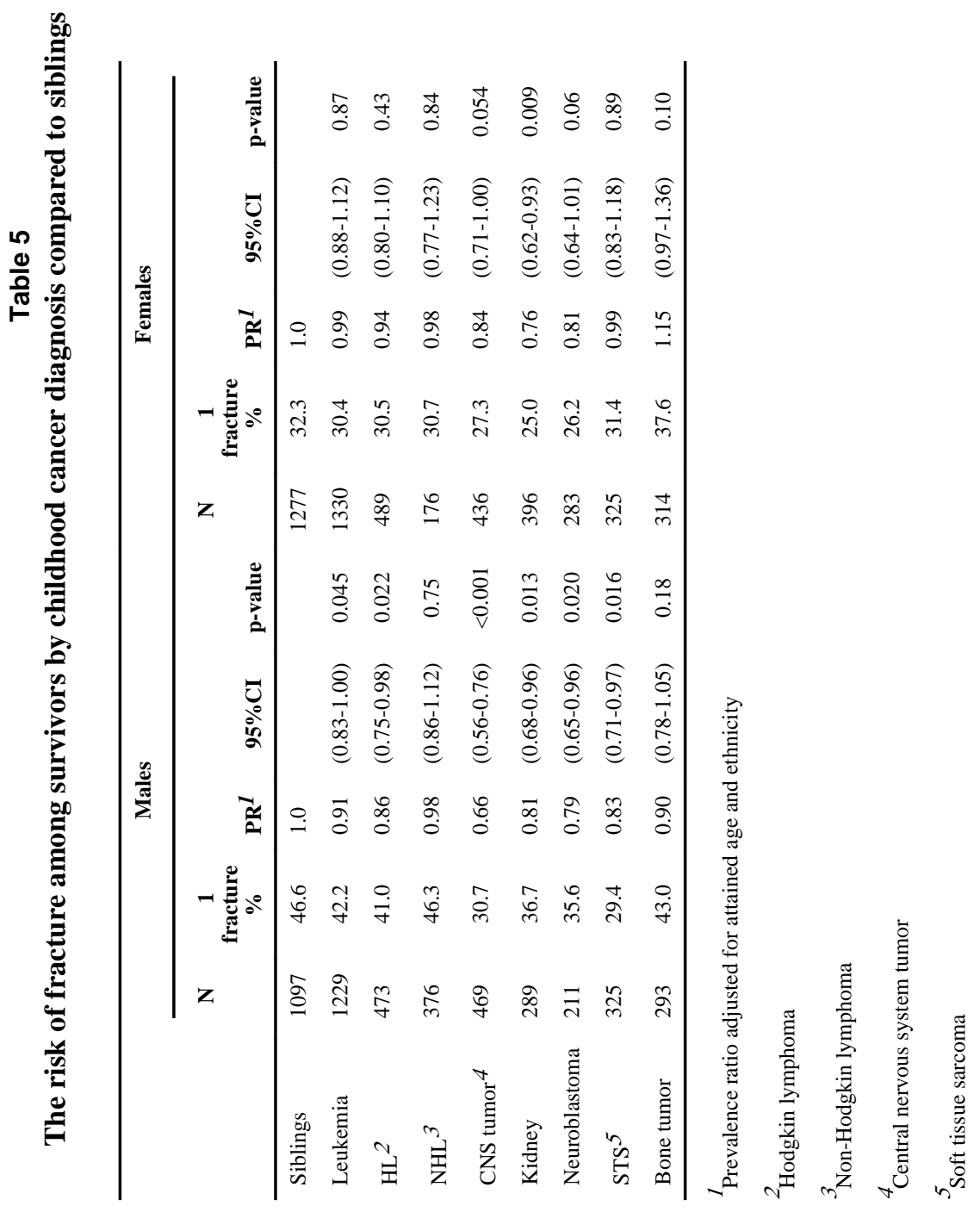

